\title{
Arti Simbolis Pahatan Naga Di Bawah Cerat Yoni Dari Singasari
}

\section{Rita Istari}

Keywords: decorative pattern, ornament, temple, statue, symbol, iconography

\section{How to Cite:}

Istari, R. (2003). Arti Simbolis Pahatan Naga Di Bawah Cerat Yoni Dari Singasari. Berkala Arkeologi, 23(1), 53-62. https://doi.org/10.30883/jba.v23i1.860

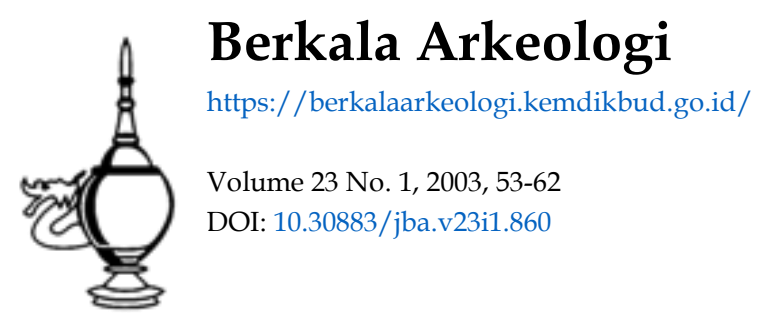

\section{(c) (1) (2)(2)}

This work is licensed under a Creative Commons Attribution-NonCommercial-ShareAlike 4. 0 International License. 


\title{
ARTI SIMBOLIS PAHATAN NAGA DI BAWAH CERAT YONI DARI SINGASARI
}

\author{
T.M. Rita Istari
}

$\mathrm{P}$ eninggalan-peninggalan arkeologi baik yang berupa bangunan, arca maupun artefak, dibuat oleh manusia pendukungnya untuk memenuhi kebutuhan hidupnya yang berupa kebutuhan rohani maupun jasmani. Artefak sebagai alat pemenuhan kebutuhan rohani dalam hal pembuatannya baik yang menyangkut penentuan bentuk maupun pemilihan dekorasinya akan terikat oleh adanya aturanaturan tertentu yang berhubungan dengan masalah keagamaan. Sebagaimana diketahui bahwa pada masa Klasik, hasil-hasil kesenian mempunyai hubungan yang erat antara hasil kesenian dengan keagamaan, maka pengamatan terhadap ragam hias yang terlukis pada benda-benda yang mempunyai nilai-nilai keagamaan sedapat mungkin diusahakan untuk mencari makna yang tersembunyi di balik ragam hias tersebut. Dalam kesenian Hindu, ragam hias pada bangunan candi atau benda-benda arkeologi dilihat dari segi teknisnya dapat dibedakan antara lain sebagai berikut: Hiasan Aktif/Konstruktif, Hiasan Teknis dan Hiasan Pasif/Dekoratif.

Hiasan Aktif / Konstruktif adalah; hiasan yang tidak dapat dipisahkan dari bangunan/benda pokoknya. Jika dipisahkan akan merusak konstruksi bangunan/benda tersebut, misalnya, hiasan pada ambang pintu dan dinding bangunan candi. Sedangkan hiasan Teknis adalah; yang mempunyai faedah dan bersifat teknis, misalnya, batu-batu penutup langit-langit dan bentuk-bentuk saluran pembuangan air/jaladwara pada bangunan candi. Lain halnya dengan hiasan Pasif/Dekoratif adalah; hiasan yang lepas dari bangunan, apabila dihilangkan tidak mempengaruhi konstruksi bangunan/benda tersebut, misalnya, hiasan pada makara, pilaster tangga naik dan sebagainya. Biasanya ragam hias yang terdapat di dalam bangunan/benda-benda peninggalan Hindu secara umum dapat digolongkan atas gambar-gambar antropomorf, gambar-gambar tumbuhtumbuhan, binatang dan ornamen-ornamen geometris (Satari; 1987). Gaya seni hias tersebut dipengaruhi unsur-unsur kebudayaan India tempat asal kesenian Hindu yang berkembang di Indonesia.

Di Kantor BP3 (Balai Pelestarian Peninggalan Purbakala) Jawa Timur yang bertempat di Kecamatan Trowulan, Kabupaten Mojokerto, banyak ditemukan benda-benda arkeologi yang tersimpan rapi di ruangan khusus maupun yang diletakkan tersebar di halaman kantor. Penulis tertarik untuk mengupas salah satu koleksi BP3 tersebut. Benda koleksi itu adalah sebuah yoni yang ditempatkan di halaman sebelah barat kantor. Sangat disayangkan bahwa kita tidak dapat mengetahui secara lengkap tentang yoni itu, hanya diketahui asalnya dari wilayah Kabupaten Malang, Jawa Timur (ditemukan kurang lebih $1 \mathrm{Km}$. dari Candi Singasari sekarang). Kemungkinan untuk 
memudahkan inventarisasi, oleh BP3 disebut yoni dari Singasari saja karena sebenarnya yoni itu merupakan barang sitaan dari pihak kepolisian Jawa Timur. Yoni tersebut masih utuh dan di bawah ceratnya terdapat pahatan berbentuk seekor naga.

Yoni menurut fungsinya dapat dikelompokkan menjadi 2 kelompok yaitu : Kelompok I, yoni yang ditempatkan di luar bangunan candi, berfungsi sebagai watu kulumpang/lapik lingga untuk upacara penetapan suatu Sima. (Haryono;1977).

Kelompok II, Yoni yang ditempatkan di dalam bangunan candi, digunakan sebagai lapik arca atau lingga dan berfungsi sebagai penyalur air pembersih arca/lingga tersebut. (Ayatrohaedi;1979). Yoni menurut arti harfiahnya dianggap sebagai lambang kewanitaan dalam agama Hindu. Hal ini berkaitan pula dengan yoni yang berada di dalam bangunan candi, mempunyai fungsi sebagai Sakti/istri dewa. Apabila yang diletakkan di atasnya adalah arca dewa Siwa yang dimanifestasikan sebagai lingga, berarti yoni tersebut menggambarkan Sakti dewa Siwa yaitu Dewi Durga atau Dewi Parwati. Yoni sebagai lapik arca/lingga sangat dipuja-puja oleh para penganutnya. Oleh sebab itulah pada waktu tertentu lingga/arca tersebut dimandikan/dibersihkan dengan melalui beberapa rangkaian upacara. Air yang mengalir dari cerat yoni itu kemudian ditampung dalam suatu wadah dan dianggap sebagai air suci.

Yoni dari BP3 mempunyai hiasan pahatan di bawah ceratnya berupa seekor naga ini termasuk dalam apa yang disebut hiasan pasif/dekoratif seperti yang telah diterangkan di atas. Berarti apabila gambar/pahatan naga itu dihilangkan, tidak akan mempengaruhi konstruksi bangunan/yoni itu sendiri. Pahatan yang digambarkan tentulah mempunyai arti religius dan nilai seni yang sangat tinggi. Ada beberapa yoni yang mempunyai pahatan naga di bawah ceratnya, baik yang terdapat di Jawa Tengah maupun Jawa Timur. Dari Jawa Tengah antara lain: yoni pada Candi Induk Prambanan. (Haryono;1980). Variasi lain misalnya yoni dengan pahatan naga dan kura-kura dapat dijumpai pada Candi Sambisari (Soediman;1976), Candi Canggal (Poerbatjaraka;1952) dan Candi Ijo (Kartoatmodjo; 1962). Dari Jawa Timur antara lain: yoni di Klinterejo, Kecamatan Sooko, Kabupaten Jombang, Yoni Lebak Jabung, Kecamatan Trowulan, Kabupaten Mojokerto dan yoni gambar di Desa Japanan, Kecamatan Mojowarno, Kabupaten Jombang (Rangkuti; 2003) dan beberapa yoni di Museum Trowulan yang tidak diketahui darimana asalnya. Yang patut disayangkan adalah yoni-yoni Jawa Timur ini sudah banyak yang tidak utuh lagi, pahatan naganya sudah rusak karena pernah dengan sengaja dipangkas oleb orang dan diperjual belikan. Jadi pada umumnya pahatan naganya tidak dapat diketahui bentuk aslinya. 
D

Letak

Bentuk

Ukuran

Asal : dari Singasari, Kabupaten Malang.

No. Inventaris : Tidak ada

: Halaman sebelah barat kantor induk PB3, Trowulan

: bujur sangkar, permukaan dan dasar sama besar

: Tinggi keseluruhan : $72 \mathrm{~cm}$

Panjang X Lebar : 80 X $80 \mathrm{~cm}$

Panjang X Lebar Lubang Tengah : 28 X $28 \mathrm{~cm}$

Kedalaman lubang tengah : $53 \mathrm{~cm}$

Panjang cerat yoni : $38 \mathrm{~cm}$

Panjang naga $: 32 \mathrm{~cm}$

Tinggi naga dari permukaan tanah/dasar : $48 \mathrm{~cm}$

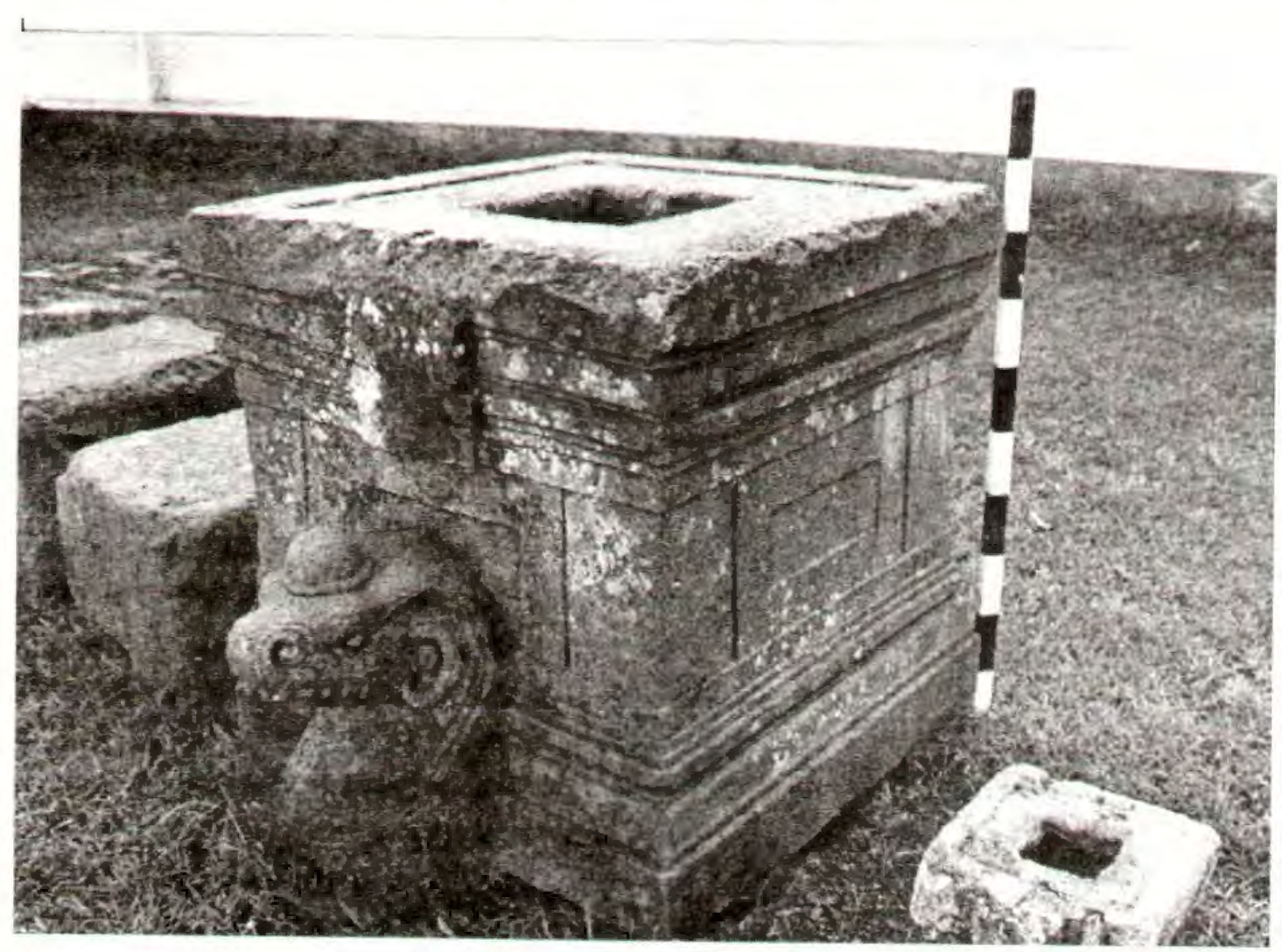

Yoni terbuat dari batu andesit warna hitam ke abu-abuan, dengan permukaan atas yang sudah tidak utuh lagi, karena pada bagian tepinya tampak bekas-bekas pengrusakan. Cerat yoni juga sudah hilang dipangkas dengan sengaja. Di bawah cerat yoni yang sudah tidak ada tersebut, terdapat pahatan naga yang se olah-olah menyangga cerat yoni, meskipun jarak antara cerat dan naga hanya sekitar $20 \mathrm{~cm}$. Naga digambarkan memakai mahkota berbentuk bulatan kecil, dengan leher mengembang. Mulut naga terkatup rapat tetapi gigi-gigi atasnya tampak rapi berderet keluar. Mata terbuka biasa dan berukuran kecil. Wajah naga kelihatan ramah, 
memakai hiasan semacam anting di telinganya dan menempel pada lehernya yang mengembang. Di bawah mulut dihiasi dengan sisik-sisik berbentuk segi empat miring (trapesium). Pada leher ini juga dihiasi dengan kalung berbentuk sulur-suluran kurang lebih selebar $7 \mathrm{~cm}$ yang sejajar dengan dasar yoni.

Balok denah persegi, dengan pelipit-pelipit yang dibuat secara simetris, berupa panilpanil/kotak-kotak yang tidak begitu dalam goresannya. Pada ke empat sisi bagian atas dan bawah dihias sama yaitu pelipit lebar, pelipit tipis yang goresannya lebih masuk ke dalam. Hiasan pelipit-pelipit ini selang-seling antara pelipit lebar kemudian pelipit tipis sebanyak tiga kali. Sedangkan pada bagian tengah bentuk panil, yang pada salah satu sisinya merupakan sandaran kepala naga dengan cara kepalanya menempel pada bagian tengah panil tersebut. Penggambaran pahatan yoni ini secara keseluruhan terkesan tampak sederhana, tetapi ada keistimewaannya yaitu pemahatannya yang sudah halus dan rapi.

\section{A. Fungsi dan arti yoni dalam agama Hindu}

Sebagaimana telah diketahui bahwa dalam agama Hindu mengenal adanya pemujaan kepada tokoh wanita. Tokoh tersebut ditafsirkan sebagai dewi Bumi atau Perthiwi yang dipuja sebagai dewi Ibu yaitu dewi Kemakmuran dan dewi Kesuburan.

Pada masa sekte Sakta berkembang, tokoh wanita juga masih dipuja. Mereka beranggapan bahwa dewa dalam menciptakan sesuatu di dunia selalu disertai istrinya/Saktinya. Kemudian timbullah aliran yang memuja Sakti tersebut dan salah satu bentuk pemujaannya adalah pemujaan kepada yoni. (Liebert;1976). Dewa Siwa dalam salah satu bentuk pemujaannya dilambangkan dalam bentuk phallus/lingga, dan merupakan satu kesatuan yang tidak dapat dipisahkan dengan yoni atau disebut juga pita lingga atau pindakha. (Rao;1971). Persatuan antara Siwa dan Saktinya atau antara lingga dan yoni diperlukan beberapa macam sesaji, dan salah satu perlengkapan upacara adalah air. Jadi sangatlah sesuai apabila dikatakan bahwa yoni berfungsi sebagai penampung air suci. Dalam pelaksanaan upacara, air tersebut disiramkan pada ujung lingga dan mengalir ke bawah kemudian keluar lewat cerat yoni. Air tersebut kemudian di bagi-bagikan kepada peserta upacara sebagai air suci/amerta.

Juga dalam upacara penetapan Sima/daerah yang menjadi daerah perdikan diperlukan batas-batas untuk daerah tersebut. Biasanya berupa sebuah tonggak batu yang diberi nama Sang Hyang Watu Sima atau Sang Hyang Teas yang mempunyai pasangan yaitu Sang Hyang Watu Kulumpang atau yoni.(Haryono;1980). Penggambaran lingga yang berupa phallus dan yoni yang melambangkan kelamin wanita bukanlah sesuatu yang tidak susila atau porno. Pemujaan lingga dan yoni terletak pada hakekat kekuatannya sebagai pencipta. Dengan kata lain pemujaannya tidak pada wujud lingga dan yoni 
tetapi pada kekuatan di balik lingga dan yoni yang merupakan unsur laki-laki dan perempuan, dalam kesatuan tertinggi atau keseluruhan yang ada. (Kempers;1959).

Menurut denahnya, yoni dapat digolongkan menjadi bermacam-macam jenis antara lain: berdenah segi tiga, segi empat, bujur sangkar, segi enam, segi delapan, segi enambelas, segi duapuluh, elips dan setengah lingkaran. Di samping cerat, yoni mempunyai lekukan yang berguna untuk menghalangi air yang disiramkan dari puncak lingga, supaya tidak tumpah tetapi keluar lewat cerat. Bagian-bagian yoni secara lengkap adalah nala (cerat), Jagati, Padma, Kantha dan lubang untuk berdirinya lingga atau arca.(Hadiyanto; 1984). Di bawah cerat biasanya ada hiasan yang berupa pahatan, seperti pahatan naga di bawah cerat yoni dari Singasari yang
dibicarakan dalam makalah ini.

Pada umumnya relief yang dipahatkan pada yoni berupa binatang naga, kura-kura, singa atau garuda. Dalam penggambarannya ada yang secara terpisah maupun berkombinasi. (Satari;1978). Variasi penempatannya pun ber macam-macam, ada yang dilukiskan di bawah cerat dan ada pula yang dilukiskan di badan yoni. Adanya pola hiasan itu kemungkinan ditentukan oleh makna simbolis yang terkandung pada unsur hiasannya. Dalam kebudayaan Hindu, penggambaran yang dianggap paling penting apabila digambarkan secara kombinasi antara : naga dengan kura-kura maupun naga dengan garuda. Ke tiga jenis binatang yang menjadi pola hiasan yoni tersebut pada intinya berhubungan dengan masalah tentang pencarian air suci amerta. (Soekmono;1952). Air sebagai simbol sumber kehidupan dan merupakan unsur yang esensiil dalam hubungannya dengan yoni.(Haryono;1980).

Penggambaran kombinasi antara naga dengan kura-kura dianggap penting karena naga melambangkan "Perthiwi" yang "memangku" dunia dan sebagai wakil dari dunia bawah. Sedang kura-kura dianggap binatang suci karena sebagai penjelmaan dewa Wisnu yang adalah pelindung dunia.(Santiko;1996). Contoh lain betapa pentingnya penggambaran naga dan kura-kura ini dapat ditemukan pada isian peripih candi di Jawa pada umumnya, di samping benda-benda lain sebagai isian peripih juga terdapat lempengan emas yang menggambarkan naga dan kura-kura tersebut. Selain itu terdapat juga pada relief-relief candi dan benda arkeologi lain.

Penggambaran kombinasi antara naga dengan garuda (contoh: yoni yang ada di Museum Sanabudaya DIY dan Museum Trowulan, Jawa Timur), tentulah ada hubungannya dengan cerita yang dianggap suci pada masa itu. Hal ini erat hubungannya dengan air suci yang diperoleh dari pencucian lingga/arca yang ditempatkan di atas yoni tersebut. Cerita yang dimaksudkan adalah cerita Garudeya yang merupakan cerita tentang pelepasan dari perbudakan. Cerita ini dimuat di dalam bagian pertama (Adiparwa) dalam Kitab Mahabharata, yang merupakan kelanjutan
dari cerita Amertamanthana. 
Supaya lebih memperjelas betapa pentingnya peranan ke tiga binatang itu terutama naga, penulis akan menguraikan secara garis besar cerita tentang Amertamanthana dan Garudeya tersebut.

\section{- Amertamanthana}

Amertamanthana adalah cerita tentang pengadukan laut untuk mendapatkan air amerta. Sedangkan pengertian Amerta, semula merupakan minuman para dewa yang mempunyai khasiat dapat menghindarkan diri dari ketuaan dan kematian bahkan dianggap pula dapat menghidupkan kembali yang telah mati. Oleh karena itulah amerta ini menjadi rebutan para dewa yang berada di dunia atas dan para daitya yang tinggal di dunia bawah. Pada suatu ketika dewa Brahma sebagai pencipta alam semesta memerintahkan para dewa dan daitya untuk bekerjasama mencari amerta dengan cara melakukan pengadukan lautan yang akan menghasilkan amerta tersebut. Sebagai alat pengaduk digunakanlah Gunung Mandara yang dianggap sebagai gunung tertinggi. Selanjutnya dewa Wisnu menjelma menjadi kura-kura yang amat besar dan berdiri di dasar laut sebagai alas Gunung Mandara jika gunung itu diputar nanti. Sedangkan dewa Wasuki menjelma menjadi ular yang sangat besar dan panjang sekali, diperkirakan cukup untuk membelit gunung tersebut. Kemudian bagian ekornya dipegang oleh para dewa dan bagian kepalanya dipegangi oleh para daitya. Secara ber ganti-ganti mereka menarik ekor atau kepala ular itu sampai Gunung Mandara terputar dan mengaduk lautan. Lama kelamaan pengadukan itu tampak hasilnya, hasil pertama kali adalah keluarnya Sura, sebagai dewi anggur, atau penggembira kahyangan. Kedua adalah Laksmi, dewi kebahagiaan yang kemudian menjadi istri dewa Wisnu. Ber turut-turut kemudian keluarlah Ucaihsrawas, seekor kuda sembrani putih yang menjadi kendaraan para dewa, Kaustubh, yang berupa manikam bercahaya yang dapat menerangi seluruh alam semesta. Pohon Parijata, yaitu pohon langit yang berbuah segala macam kekayaan, kebahagiaan serta kehidupan di seluruh dunia. Hasil terakhir dari pengadukan itu adalah keluarnya dewa Dhanwantari, yang dianggap sebagai tabib kahyangan, di tangannya memegang sebuah guci yang berisi Amerta. Peristiwa yang kemudian terjadi para dewa dan para daitya berebutan untuk mendapatkan amerta tersebut. Akhir cerita ini, kemenangan berada di pihak para dewa. Oleh sebab itulah menurut kepercayaan Hindu, para dewa dapat hidup abadi selamanya.(Soekmono;1980).

Dalam naskah Jawa Kuna (Tantu Panggelaran), dikisahkan pula suatu cerita yang mirip dengan cerita Amertamanthana yaitu tentang peranan naga dan kura-kura. Menurut cerita tersebut, pada jaman dahulu sebelum negeri ini didiami manusia, Pulau Jawa ter apung-apung di lautan, oleh sebab itulah Pulau Jawa selalu terguncang bergerak. Para dewa kemudian menghadap Bhatara Guru, rajanya para dewa, untuk meminta saran bagaimana sebaiknya agar pulau tersebut bisa tenang. Atas saran Bhatara Guru, para dewa berusaha memindahkan Gunung Mahameru dari 
Jambhudwipa (India) ke Jawadwipa (Jawa). Untuk mengangkat puncak Gunung Mahameru ke Jawa juga bukan masalah yang mudah. Upaya ini hanya berhasil mengangkat puncak gunung saja, karena ternyata gunung tersebut tertanam di bumi dengan sangat kuatnya. Kemudian dewa Wisnu merubah dirinya menjadi seekor kurakura yang sangat besar, dan seorang dewa lainnya merubah dirinya menjadi seekor ular yang dapat membelit seluruh Gunung Mahameru tadi, dan meletakkannya di atas punggung kura-kura. Dengan cara itulah Gunung Mahameru dapat dipindahkan ke Jawa. Selanjutnya gunung tersebut diletakkan tepat di tengah-tengah pulau, sehingga Pulau Jawa bisa tenang dan tidak terguncang lagi. (Pigeaud; 1924).

Melihat cerita-cerita di atas, tampaklah disini betapa penting peranan ular/naga, meskipun didampingi oleh binatang lainnya. Peranan naga yang menonjol adalah penggunaan Gunung Mandara sebagai alat pengaduk lautan dengan kura-kura sebagai alas dan ular sebagai pembelit. Juga tentang pemindahan Gunung Mahameru yang disamakan dengan Gunung Mandara dari India ke Jawa, dengan menggunakan kurakura sebagai alas gunung dan ular sebagai pengikatnya.

\section{- Garudeya}

Konon, ada dua orang bersaudara yang bernama Kadru dan Winata, kedua wanita ini menjadi istri Bhagawan Kacyapa. Karena setelah lama menikah dan tidak mempunyai anak, mereka meminta kepada Bhagawan agar diberi keturunan. Permintaan dikabulkan oleh Bhagawan dengan cara masing-masing diberi telur yang harus dierami. Sesudah sampai waktunya telur Kadru menetas lebih dahulu berupa seribu ekor ular. Karena iri hati Winata memecahkan satu telurnya, karena belum saatnya menetas maka telur itu berupa seorang anak yang belum sempurna bentuknya dan kemudian diberi nama Aruna. Karena sebenarnya Aruna belum waktunya lahir, maka dia marah dan mengutuk ibunya kalau kelak ibunya akan menjadi budak saudaranya sendiri. Sebagai syarat untuk membebaskan diri dari perbudakan tersebut harus menunggu menetasnya telur yang satunya lagi, dan dialah yang akan membebaskan
Winata.

Pada suatu waktu Kadru dan Winata mendengar bahwa pengadukan laut Ksira menghasilkan antara lain seekor kuda sembrani putih yang diberi nama Ucaihsrawas (dikisahkan dalam cerita Amertamanthana). Kedua wanita itu bertaruh tentang warna ekor kuda sembrani tersebut, Winata menebak warna putih, sedangkan Kadru menebak warna hitam, dengan perjanjian siapa yang kalah akan menjadi budak bagi yang menang. Sebetulnya pada saat itu Kadru kalah, tetapi dengan akal licik dia memperdaya Winata yaitu dengan jalan menyuruh anaknya yang berupa ular untuk menyemprot ekor kuda tersebut dengan bisanya sehingga berwarna hitam. Sebab dianggap kalah, Winata menjadi budak Kadru, dengan demikian kutukan anak Winata menjadi kenyataan. Tidak berapa lama, menetaslah telur Winata yang tersisa berupa 
seekor garuda yang sangat besar. Untuk membebaskan ibunya dari perbudakan, garuda menyanggupi mencari air amerta sebagai syarat pembebasan yang diajukan oleh Kadru dan anak-anaknya. Setelah melalui berbagai rintangan, garuda berhasil mendapatkan amerta. Dalam perjalanan pulang, garuda bertemu dengan dewa Wisnu yang memintanya untuk menjadi kendaraan/Wahananya. Selanjutnya garuda menyerahkan amerta kepada Kadru dan anak-anaknya, dengan demikian Winata telah terbebas dari perbudakan. Sebelum meminum air tersebut, garuda berpesan agar anakanak Kadru mandi terlebih dahulu. Hal ini memang disengaja agar ular-ular tersebut lengah, sehingga amerta dapat dicuri oleh para dewa. Sebagai petugas mencuri dilakukan oleh dewa Indra pada waktu mereka sedang mandi. Karena dewa Indra tergesa-gesa melarikan diri, ada sebagian amerta yang tertumpah dan tercecer pada daun ilalang. Ular-ular tersebut dengan putus asa karena sedih kehilangan amerta, mengetahui kalau ada yang tercecer di daun ilalang, mereka ber ramai-ramai menjilati ilalang tersebut. Karena tepi daun ilalang itu tajam, mengakibatkan lidah ular terbelah dua atau bercabang sampai sekarang. (Widyatmanto;1968).

\section{B. Tahun pembuatan dan pembuatnya.}

Mengetahui tahun berapa yoni ini dibuat sangatlah sulit sebab kurangnya data yang dapat membantu untuk menentukannya. Tempat asal yoni inipun sulit diketahui, karena dalam daftar inventaris tidak disebutkan, hanya diketahui bahwa yoni tersebut merupakan tinggalan arkeologi yang berhasil diselamatkan dari pencurian dan sebagai barang sitaan dari pihak kepolisian yang kemudian diserahkan kembali kepada BP3 Jawa Timur di Trowulan, Kabupaten Mojokerto.

Tentang siapa pembuat yoni tersebut atau berasal dari mana sulit diketahui pula. Hanya yang jelas yoni ini dibuat pada masa Klasik/Hindu, sebagai sarana suatu upacara pemujaan dengan tujuan untuk mendapatkan air suci amerta.

$\mathrm{M}$

elihat uraian di atas dapatlah diambil suatu kesimpulan bahwa:

* Yoni berhias naga sangat erat hubungannya dengan fungsi yoni dan air suci amerta.

* Yoni dengan lingga/arca kemungkinan dipuja sebagai tempat pelepasan, contoh seperti dalam cerita Garudeya tersebut.

Demikianlah diketahui sedikit gambaran tentang peranan naga pada yoni atau bendabenda suci lainnya. Pahatan dalam kesenian Hindu tidaklah berarti hanya merupakan unsur-unsur dekoratif saja, akan tetapi mengandung pula makna simbolis dalam falsafah hidup manusia. 
Yoni yang dibuat dari batu andesit, rupa-rupanya juga mempunyai arti sendiri-sendiri. Batu untuk yoni dari proses terjadinya dapat digolongkan menjadi empat jenis yaitu: batu amat muda (bala), batu muda (Yuya), batu tengah (Madnya) dan batu tua (wreddha). Di samping itu juga dapat digolongkan menjadi: batu jantan, batu betina dan batu netral. Warna batu juga mempunyai arti sendiri pula yaitu: putih melambangkan kesamaan, merah melambangkan kejayaan, kuning melambangkan kesejahteraan dan hitam melambangkan kesuburan. (Hadiyanto;1984). Batu untuk yoni biasanya jenis batu betina. (Rao;1971). Kenyataan ini sesuai dengan pendapat yang mengatakan bahwa yoni adalah unsur perempuan. Sebagian besar yoni terbuat dari batu andesit warna hitam, hal ini selaras dengan arti yoni sebagai lambang perempuan yang berhubungan dengan kesuburan.

\section{KEPUSTAKAAN}

Ayatrohaedi,dkk; 1979; Kamus Istilah Arkeologi; Yayasan Pembangunan;Jakarta

Hadiyanto, Manarudin; 1984; Fungsi Yoni Dengan Hiasan Kala Pada Ceratnya di Situs Gunungsari, Skripsi Sarjana Muda Fak. Sastra UGM, Yogyakarta.

Haryono, Timbul; 1977; "Sang Hyang Kulumpang di dalam Upacara Penetapan Sima"; Humanitas, No. 1 Th. I; Fakultas Sastra dan Kebudayaan, UGM; Yogyakarta.

Haryono, T. (1980). Singa Dalam Kesenian Hindu Di Jawa Tengah. Berkala Arkeologi, 1(1), 42-51. https://doi.org/10.30883/jba.vli1.275

1980; Gambaran Tentang Upacara Penetapan Sima; Majalah Arkeologi; Lembaga Arkeologi Fak. Sastra UGM, Yogyakarta.

Kartoatmodjo, Sukarto,MM; 1962; Tjandi Idjo (Suatu Obyek Penyelidikan Kepurbakalaan); Skripsi Doktoral Fakultas Sastra dan Kebudayaan, UGM; Yogyakarta.

Kempers, Bernet,A.J; 1959; Ancient Indonesia Art; van der Peet; Amsterdam.

Liebert, Gosta; 1976; Iconograpic Dictionary of the Indian Religions, Studies in South Asian Culture Volume V; E.J.Brill; Leiden.

Poerbatjaraka, R.Ngt; 1952; Riwayat Indonesia I; Yayasan Pembangunan, Jakarta. 
Pigeaud, Th.G. Th; 1924; De Tantu Panggelaran; Uitgegeven, Vertaald en Toegelicht; Disertasi; Leiden.

Rao, Gopinatha, T.A.; 1971; Elements of Hindu Iconography Vol. II part 1; Varanasi Indological Book House.

Rangkuti, Nurhadi; 2003; "Menelusuri Batas Kota Majapahit di Situs Trowulan, Jawa Timur"Laporan Penelitian Arkeologi; Balai Arkeologi Yogyakarta.

Satari, Suyatmi; 1987; "Seni Hias Ragam dan Fungsinya"Diskusi Ilmiah Arekeologi II; Jakarta.

Santiko, Hariani; 1996; "Seni Bangunan Sakral Masa Hindu-Buddha di Indonesia (Abad VII-XV Masehi) Analisis Arsitektur dan Makna Simbolik", Jurnal Arkeologi Indonesia No. 2, Edisi Maret; Jakarta

Soediman; 1976; Sepuluh Tahun Ekskavasi Candi Sambisari (1965-1975); Yayasan Penerbitan Jakarta.

Soekmono; 1952; "Amertamanthana"Amerta 1; Dinas Purbakala Republik Indonesia..

Widyatmanto, Siman; 1968; Adiparwa I, Cetakan Ke tiga; U.P. Spring, Yogyakarta. 